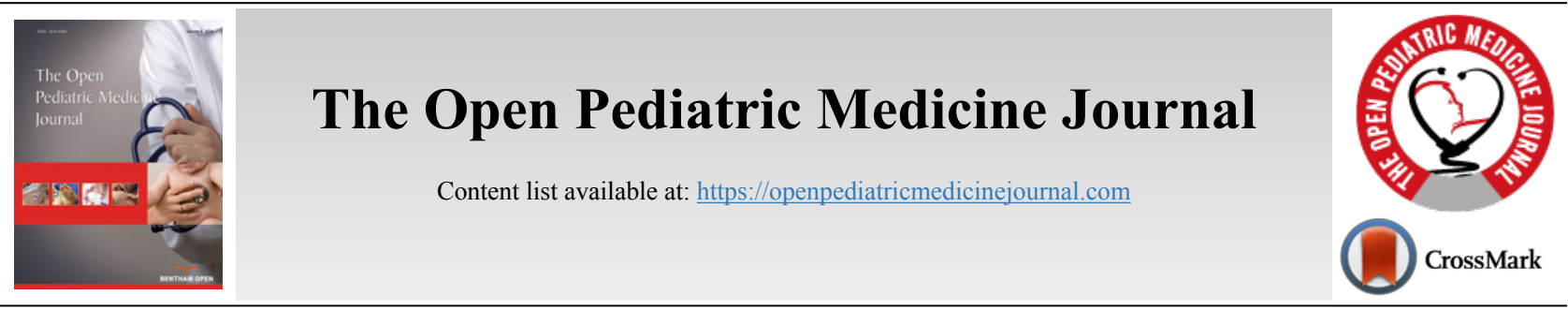

CASE REPORT

\title{
Anaplastic Large Cell Lymphoma ALK-Negative: About a Rare Pediatric Case Report
}

\author{
Louachama Ouidad $^{1, *}$, Elbaz Meriem ${ }^{2}$ and El Houdzi Jamila ${ }^{1}$ \\ ${ }^{I}$ Department of Pediatric Hematology and oncology, University Hospital Mohammed VI, Marrakesh separate by comma, Morocco \\ ${ }^{2}$ Department of Pediatric Hematology and oncology, Faculty of Medicine, University Cadi Ayad, Marrakesh, Morocco
}

\begin{abstract}
:
Introduction:

Anaplastic Large Cell Lymphomas (ALCL) are rare in childhood but clinically aggressive. The contemporary World Health Organization (WHO) classification of hematologic malignancies recognizes two distinct subtypes of systemic ALCL: Anaplastic Lymphoma Kinase (ALK)-negative, and ALK-positive.

Case report:

We report a rare pediatric observation of cutaneous nodule revealing an Anaplastic Large Cell Lymphoma (ALCL) ALK - cutaneous, muscular and ganglionic. It was classified according to who classification, treated by polychemotherapy with good outcome.

Conclusion:

ALCL encompasses several distinct clinicopathologic entities with unique genomic under printing. This rare pediatric observation of ALCL presents a new discussion on a pathology still incompletely known.
\end{abstract}

Keywords: Anaplastic large cell lymphoma, Negative ALK, Child, Polychemotherapy, Ultrasound, Hematologic malignancies.

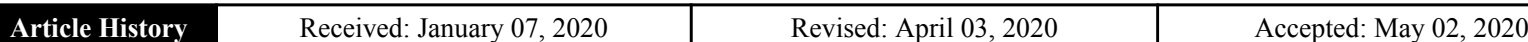

\section{INTRODUCTION}

Anaplastic Large Cell Lymphoma (ALCL) accounts for $10 \%$ to $30 \%$ of all childhood lymphomas and approximately $5 \%$ of all non-Hodgkin's lymphoma. ALCL is considered to be a T-cell non-Hodgkin's lymphoma that can be divided into two major groups with distinct genetic, immunophenotypic, and clinical behaviors [1].

ALCL-ALK - is generally responsive to doxorubicincontaining chemotherapy, but relapses are frequent. CHOP (Cyclophosphamide, Doxorubicin, Vincristine, Prednisone) is the most commonly used regimen to treat systemic ALCL with complete remission rates of $56 \%$, and a 10 -year DFS of $28 \%$ $[2]$.

\section{OBSERVATION}

A 10-year-old child, without any medical history, ten

\footnotetext{
* Address correspondence to this author at the Department of Pediatric Hematology and oncology, University Hospital Mohammed VI, Marrakesh, Morocco, E-mail: louachamaouidad@gmail.com
}

months ago presented tow axillary lymphadenopathies without inflammation and he developed a nodule in the right dorsal region, hard skin lesion, with a weight loss and fever.

The ultrasound showed a mass measuring $22 * 10 \mathrm{~mm}$ hypoechoic well limited with a hyperechoic center sitting in the right serrated muscle, multiple right axillary lymphadenopathies.

$\mathrm{He}$, first, consulted with the general surgeon and complete resection was made. The clinical exam showed two axillary lymph nodes of $1 \mathrm{~cm}$ measured without skin inflammation or other symptoms and the general examination was normal.

Pathology exam and immunohistochemistry (IHC) showed diffuse undifferentiated proliferative process, polymorphic cell component, polyhedral, superimposed with anarchic orientation, some multinucleate, hyperchromic nuclei, anisocaryotes, strong nucleolization, frequent mitoses vacuolar cytoplasm 20 to $30 \%$ and IHC profil: Anti CD30+, anti ALK -, anti CD15 -, anti CD 20 -, anti CD 79a -, anti-CD138 -, anti CD 3 -; in conclusion to non-Hodgkin's lymphoma with large 
anaplastic cells of phenotype CD 30+, ALK (-).

After confirmation of diagnosis, further analysis to look for metastasis was done with the following findings; the CSF, absence of abnormal cells with hemoglobin: 12.9, VGM: 83 , TCMH: 27.2 , platelets: 293,000 and neutrophils: 3370

The chest, abdominal, and pelvic computed tomography, bone scans, bone marrow biopsy, lumbar puncture and echocardiogram were performed, demonstrating no evidence of disease and spinal fluid was normal.

The lymphoma was classified as WHO classification ALCL - ALK due to the lack of ALK and stage II E according to the ANN ARBOR staging system.

The patient was treated by low-risk group protocol comprising dexamethasone, methotrexate, cyclophosphamide, doxorubicin and ifosfamide (2 AM cures and $2 \mathrm{BM}$ cures).

The clinical examination noted a regression of lymph nodes in a few days and the radiological evaluation was good in 4 months.

\section{DISCUSSION}

Anaplastic Large Cell Lymphomas (ALCL) are two separate diagnostic entities in the 2017 WHO Classification, ALK+ ALCL and ALK- ALCL, with implant-associated ALCL (BIALCL) defined as a temporary entity.

The most common morphology in ALCL is a diffuse proliferation of large, atypical neoplastic cells, diffusely erasing the normal nodal architecture, with variable sinus involvement [3]. So, the diagnosis of ALCL is based on which "hallmark cells" and immunopositivity of hallmark cells for CD30+ are present [4].

In contrast to ALK+ counterpart, ALCL-ALK- patients are generally older, with a median age at diagnosis of 54-61 years, compared with 27 years for the first group; the male-to-female ratio is 0.9 , being similar between ALK groups [2], and ALCLALK - is very rarely found in children [3].

Clinical features of ALK- ALCL at diagnosis are similar to those of ALK+ ALCL and presentation is usually with rapidly progressing lymphadenopathy and frequent constitutional symptoms. Once again, the central nervous system, testicular, and bone marrow involvement are uncommon. The majority of patients are diagnosed with advanced stage and intermediate-high or high IPI score [4].

ALCL-ALK- occurs with lymph node involvement in approximately $50 \%$ of cases; extranodal spread ( $20 \%$ of cases) is less frequent than in the ALK-positive form [2]. The most common extranodal localizations in ALCL-ALK- are skin, liver and lung damage, compared to bone and soft tissue in ALCL-ALK + [5].

In our case, skin lesions and soft tissues were the only sites found.

The optimal therapy for ALCL-ALK- is controversial due to the rarity of this lymphoma, heterogeneity clinical trial, and the lack of randomized trials focused on this disease [2].

Surgical excision and local radiation are the main forms of treatment with systemic chemotherapy usually reserved for the disseminated or extracutaneous disease [6]. There has also been the use of targeted therapy in PC-ALCL, specifically antibodies against CD30 [7].

Cyclophosphamide, doxorubicin, vincristine, and prednisone, are the main products used for treatment (CHOP), but these provide unsatisfactory results. While overall and complete remission rates are $70-80 \%$ and $50 \%$ respectively, 5year progression-free survival rates range from $30 \%$ to $55 \%$ $[8,9]$.

Chemotherapy for peripheral $\mathrm{T}$-cell lymphomas has been derived from experiences in aggressive B-cell lymphoma. $\mathrm{CHOP}$ is the most commonly used regimen to treat systemic ALCL [2].

Similarly, our patient was treated by polychemotherapy based on cyclophosphamide, methotrexate, doxorubicin, and isofosfamide with good outcome in a short time.

The use of intensified regimens did not produce superior results to CHOP treated patients [10].

The prognosis in patients with ALK- ALCL was historically considered poor and similar to other nodal types of Peripheral T Cell Lymphoma (PTCL) [9], but in children, this lymphoma is rare, so the prognosis is unknown.

\section{CONCLUSION}

Through this original pediatric observation of ALCL ALK, it is concluded that the histological diagnosis is the most important part of the management of ALCL. Classification is also necessary to adopt the right treatment.

\section{CONSENT FOR PUBLICATION}

Written informed consent was obtained from the parents when they were enrolled.

\section{STANDARD FOR REPORTING}

CARE guidelines and methodology were followed to conduct the study.

\section{FUNDING}

None.

\section{CONFLICT OF INTEREST}

The authors declare no conflict of interest, financial or otherwise.

\section{ACKNOWLEDGEMENTS}

Declared none.

\section{REFERENCES}

[1] Ju E, Adigun C, Dunphy C, Gold S, Morrell DS. Anaplastic large cell lymphoma: An unusual presentation in a 7-year-old girl. Pediatr Dermatol 2012; 29(4): 498-503

[http://dx.doi.org/10.1111/j.1525-1470.2011.01465.x] [PMID: 21967522]

[2] Ferreri AJM, Govi S, Pileri SA, Savage KJ. Anaplastic large cell lymphoma, ALK-negative. Crit Rev Oncol Hematol 2013; 85(2): 206-15. 
[http://dx.doi.org/10.1016/j.critrevonc.2012.06.004]

[PMID: 22789917]

[3] Andrei Shustov, Lorinda Soma, C Querfeld, et al. Anaplastic large cell lymphoma: Contemporary concepts and optimal management. Eds TCell and NK-Cell Lymphomas, Cancer Treatment and Research 176 [http://dx.doi.org/10.1007/978-3-319-99716-2_6]

[4] Delsol G, Brugieres L, Gaulard P, et al. Anaplastic large cell lymphoma, ALK-positive and anaplastic large cell lymphoma ALKnegative. Haematol Meet Rep 2009; 3: 51-7.

[5] Savage KJ, Harris NL, Vose JM, et al. International Peripheral T-Cell Lymphoma Project. ALK- anaplastic large-cell lymphoma is clinically and immunophenotypically different from both ALK+ ALCL and peripheral T-cell lymphoma, not otherwise specified: report from the International Peripheral T-Cell Lymphoma Project. Blood 2008; 111(12): 5496-504.

[http://dx.doi.org/10.1182/blood-2008-01-134270] [PMID: 18385450]

[6] Brown RA, Fernandez-Pol S, Kim J. Primary cutaneous anaplastic large cell lymphoma. J Cutan Pathol 2017; 44: 570-7. [cited 2017 Sep
14], Available from: http:// www.ncbi.nlm.nih.gov/ pubmed/

[7] Khoan $\mathrm{Vu}, \mathrm{Ai}$ Weiyun. Update on the treatment of anaplastic large cell lymphoma. Cur Hematol Malignan Rep 2018; 13: 135-41.

[8] Adams SV, Newcomb PA, Shustov AR. Racial patterns of peripheral T-cell lymphoma incidence and survival in the united states. J Clin Oncol 2016; 34(9): 963-71.

[http://dx.doi.org/10.1200/JCO.2015.63.5540] [PMID: 26962200]

[9] Savage KJ, Harris NL, Vose JM, et al. International Peripheral T-Cell Lymphoma Project. ALK- anaplastic large-cell lymphoma is clinically and immunophenotypically different from both ALK+ ALCL and peripheral T-cell lymphoma, not otherwise specified: report from the International Peripheral T-Cell Lymphoma Project. Blood 2008; 111(12): 5496-504.

[http://dx.doi.org/10.1182/blood-2008-01-134270] [PMID: 18385450]

[10] Medeiros LJ, Elenitoba-Johnson KS. Anaplastic large cell lymphoma. Am J Clin Pathol 2007; 127(5): 707-22.

[http://dx.doi.org/10.1309/R2Q9CCUVTLRYCF3H] 17511113]

\section{(C) 2020 Ouidad et al.}

This is an open access article distributed under the terms of the Creative Commons Attribution 4.0 International Public License (CC-BY 4.0), a copy of which is available at: (https://creativecommons.org/licenses/by/4.0/legalcode). This license permits unrestricted use, distribution, and reproduction in any medium, provided the original author and source are credited. 